\title{
Out with the new and in with the old: Extracorporeal membrane oxygenation for massive hemorrhage after pulmonary endarterectomy
}

\author{
Dimitri Kalavrouziotis, MD, and Francois Dagenais, MD
}

\author{
From the Department of Cardiac Surgery, Quebec Heart and Lung Institute, Quebec City, Canada. \\ Disclosures: Authors have nothing to disclose with regard to commercial support. \\ Received for publication Sept 21, 2017; accepted for publication Oct 7, 2017; available ahead of print Nov 8 , \\ 2017 \\ Address for reprints: Francois Dagenais, MD, Department of Cardiac Surgery, Quebec Heart and Lung Institute, \\ 2725 chemin Sainte-Foy, Quebec City, Quebec, Canada G1V 4G5 (E-mail: francois.dagenais@fmed.ulaval. \\ ca). \\ J Thorac Cardiovasc Surg 2018;155:650 \\ $0022-5223 / \$ 36.00$ \\ Copyright $(c) 2017$ by The American Association for Thoracic Surgery \\ https://doi.org/10.1016/j.jtcvs.2017.10.031
}

In this issue of the Journal, Guth and colleagues ${ }^{1}$ present their results after the use of venoarterial extracorporeal membrane oxygenation (VA-ECMO) for catastrophic pulmonary hemorrhage after pulmonary endarterectomy (PEA). The authors have a vast collective experience with PEA for chronic thromboembolic pulmonary hypertension: 396 patients over 3 years. The patients in this study are an extremely challenging group, with one third having Jamieson class III disease for which surgical extirpation of distal disease can a daunting task. This study specifically focused on 8 patients who required a short course of VA-ECMO for massive endobronchial hemorrhage refractory to medical and ventilatory management after weaning of cardiopulmonary bypass after PEA. A heparin-coated circuit was used connected to the central cannulas used for cardiopulmonary bypass, which allowed for full reversal of heparin and aggressive correction of any coagulopathy to promote hemostasis of the endobronchial bleeding source. The average duration of ECMO support was 49 minutes, and all patients were weaned off ECMO in the operating room of the initial PEA operation. By using this strategy, bleeding sites were effectively sealed off and 7 of the 8 patients were discharged alive with good midterm outcome.

Uncontrollable endobronchial hemorrhage is a devastating complication after PEA. Published case series and isolated single-patient reports describing ECMO postPEA tend to be confounded by type of ECMO (venovenous and VA) and indication (reperfusion injury, persistent pulmonary hypertension, pulmonary hemorrhage). This article shows that a short course of VA-ECMO with full reversal of coagulopathy can be a lifesaving maneuver for patients undergoing PEA complicated by pulmonary hemorrhage.

This remains a small series, and as the worldwide experience with not only PEA surgery but also PEA among patients with a high burden of distal disease increases, so will

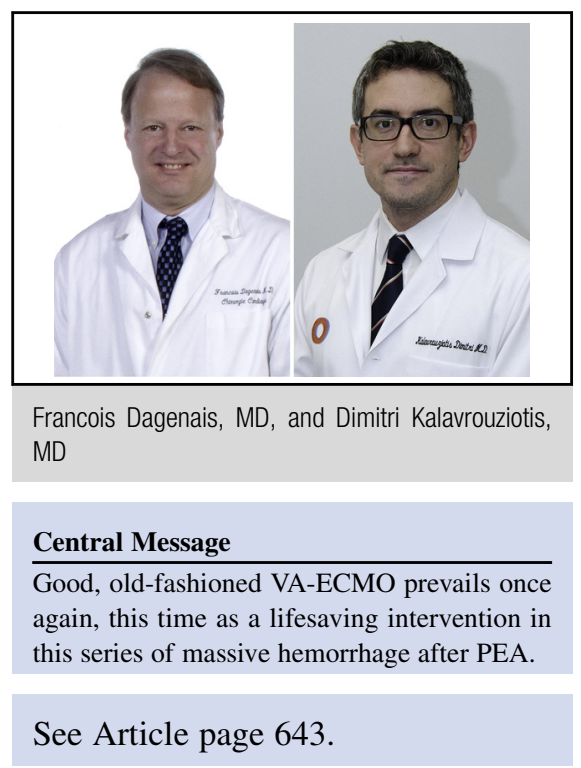

our understanding of how to best approach these patients. Hospital systems are increasingly scrutinized for cost containment. If with further experience the duration of ECMO remains less than 1 hour in this subset of patients, the use of a less expensive nonheparin-coated circuit may be an option because clotting within the circuit would not be expected to occur. This hypothesis merits further investigation.

This study reinforces the notion that good, old-fashioned ECMO continues to be a key player in the field of short-term mechanical circulatory support (MCS). Despite the emergence of novel percutaneous and surgical MCS devices, the use of ECMO continues to increase in the United States. ${ }^{2}$ Its versatility in terms of cannulation options and biventricular support, widespread availability, and relatively low cost are just some of the factors that continue to make it the primary short-term MCS device in many centers.

\section{References}

1. Guth S, Wiedenroth CB, Wollenschläger M, Richter MJ, Ghofrani HA, Arlt M, et al. Short-term venoarterial extracorporeal membrane oxygenation for massive endobronchial hemorrhage after pulmonary endarterectomy. J Thorac Cardiovasc Surg. 2018;155:643-9.

2. Squiers JJ, Lima B, DiMaio JM. Contemporary extracorporeal membrane oxygenation therapy in adults: fundamental principles and systematic review of the evidence. J Thorac Cardiovasc Surg. 2016;152:20-32. 